\title{
What Causes the Dependency between Perceived Aesthetics and Perceived Usability?
}

\author{
Martin Schrepp ${ }^{1 *}$, Raphael Otten ${ }^{2}, K_{\text {Kerstin Blum }}^{1}$, Jörg Thomaschewski² \\ ${ }^{1}$ SAP AG (Germany) \\ ${ }^{2}$ University of Applied Sciences Emden/Leer (Germany)
}

Received 5 May 2020 | Accepted 12 December 2020 | Published 22 December 2020

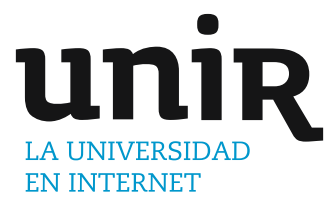

\section{ABSTRACT}

Several studies reported a dependency between perceived beauty and perceived usability of a user interface. But it is still not fully clear which psychological mechanism is responsible for this dependency. We suggest a new explanation based on the concept of visual clarity. This concept describes the perception of order, alignment and visual complexity. A high visual clarity supports a fast orientation on an interface and creates an impression of simplicity. Thus, visual clarity will impact usability dimensions, like efficiency and learnability. Visual clarity is also related to classical aesthetics and the fluency effect, thus an impact on the perception of aesthetics is plausible. We present two large studies that show a strong mediator effect of visual clarity on the dependency between perceived aesthetics and perceived usability. These results support the proposed explanation. In addition, we show how visual clarity of a user interface can be evaluated by a new scale embedded in the UEQ+ framework. Construction and first evaluation results of this new scale are described.

\section{KEYWORDS}

Usability, Aesthetics, Visual Clarity, Layout, User Experience.

\section{INTRODUCTION}

$\mathrm{T}$ be successful in today's quite competitive markets, products must be easy to use and should have an attractive and beautiful design. Research focused for a long period of time mainly on usability aspects (for example, efficiency, learnability, intuitive use, controllability or error tolerance) of products. In the last decade the focus widened to cover also user experience aspects [1], [2] (for example, aesthetical impression, stimulation or novelty). A natural question is how these usability aspects and user experience aspects relate to each other.

At first sight, beauty and usability seem to be unrelated quality aspects of a user interface, which can be designed and developed independently. But several influential studies [3], [4], [5] demonstrated that perceived aesthetics or beauty has an impact on the perceived usability of a product. This finding is often condensed in the well-known statements What is beautiful is usable [5] or Attractive things work better [6].

But the strength of the influence of perceived aesthetics on perceived usability varies between studies. Many studies found just a small influence or no effect at all [7], [8]. In addition, some authors report a reverse effect from perceived usability to perceived aesthetics (short: What is usable is beautiful) [9], [10], i.e. a good impression concerning the usability of a product improved the visual appeal of this product.

Thus, the effect seems to depend on different factors that vary between studies. The aesthetic impression of a user interface can be manipulated by many variables (colour of UI elements, typography, alignment, grouping, etc.).

* Corresponding author.

E-mail address: martin.schrepp@sap.com
The same is true for the usability. Quite different interaction styles can be used for the design of a user interface. In addition, the type of the investigated product may also have an impact here. For example, two recent papers [11], [12] showed that the importance of single UX aspects differ massively between product types. And of course, the importance of the UX aspects like aesthetics, learnability or efficiency has some impact on the judgement of subjects concerning this aspect and thus has an influence on whether a dependency between such ratings exists or not.

Since the effect of aesthetical impression on perceived usability or actual performance depends on so many variables, the question of how such an influence can be explained by psychological processes is quite important. A good explanation will help to understand which factors play a role and thus to predict under which circumstances we can expect a positive impact of the beauty of an interface on the perceived usability or even performance measures and under which conditions such an effect is unlikely.

Several psychological mechanisms have been proposed to explain the dependency between perceived aesthetics and perceived usability.

A popular explanation by Don Norman [6] assumes that the mood or emotional state of the user is responsible for this dependency. From psychological research we know [13] that a positive emotional state of a person improves his or her creativity and flexibility in problem solving. A negative emotional state on the other hand favours a systematic, inflexible and analytical problem-solving behaviour [14].

When interacting with a user interface, a user in a good mood should be more likely to overcome problems with creative ideas and would therefore judge them as less severe. A user in a bad mood, on the other hand, will be more focused on problematic details. Therefore, a user in a bad mood should assess the usability of a user interface 
worse than a user in a good mood [6].

The basic idea behind Norman's explanation is that a beautiful design of a product causes a positive mood, while an ugly design causes a negative mood. Several papers have indeed shown that the design of a product can influence the mood of its users [15], [16]. The mood or emotional state of the user acts in this explanation as a mediator variable between perceived aesthetics and perceived usability.

A potential weakness of this explanation is that it offers no good explanation for the positive impact of perceived usability on aesthetic impression (short: What is usable is beautiful), which is found in two studies [9], [10] as already mentioned above.

Another often cited explanation is based on the attractiveness stereotype (the so-called HALO-effect). Several psychological studies, see for example [17], [18], have shown that people associate an attractive appearance (which is directly observable when they meet an unknown person for the first time) with other desirable, logically unrelated properties of humans, for example social competency, empathy or intelligence (which are not directly observable).

Studies in consumer research show that there is a similar effect in the judgement of products (often named evaluative consistency). This concept describes the tendency of people to infer missing product information from an overall evaluation of the product. For example, if a product is placed in a higher price segment often a high quality is assumed [19]. If we transfer this to user interfaces, then missing information concerning usability of a product should be inferred from the directly visible aesthetical impression of the user interface. This explanation is especially convincing if users have not interacted heavily with a product when they make their judgement, since in this state they have not much information about the quality of the interaction design and thus rely on their judgements concerning the directly visible graphical quality.

The general impression model [20] assumes that the overall impression of an object influences single aspects of the impression. Thus, if a user has a good overall impression of a product, he or she will also judge single aspects, for example aesthetics or usability, positively and vice versa.

A study [9] that compared both explanations could not clearly decide which one is more adequate. Both explanations were not able to explain the resulting data in this study.

In this paper, we propose a third explanation for the dependency between perceived aesthetics and perceived usability. The basic idea behind this explanation is to assume a common factor in product perception that influences both the perception of aesthetics and usability. This common factor would thus explain a dependency in both directions.

\section{Visual Clarity as COMmon Factor}

What do we mean by the term visual clarity and why does it impact both aesthetic impression and perceived usability?

In [21] two components of aesthetic impression are distinguished. The concept of classical aesthetics describes design aspects like symmetry, clarity and order. On the other hand, expressive aesthetics focuses of creativity and originality of the design. Thus, terms like clear, clean, symmetrical, organised and ordered represent classical aesthetics, while terms like creative, original or sophisticated represent expressive aesthetics.

The VISAWI questionnaire [22], a standard questionnaire to measure visual aesthetics of web pages, contains also some items that point in the direction of classical aesthetics, for example The layout appears well-structured.
Many experimental papers also point in this direction. To illustrate this, we describe a few examples. In [23] it was shown that balance and symmetry of the layout improve the aesthetic impression of a design. A popular measure for layout complexity [24] uses mainly alignment of elements and variety of element sizes to calculate the complexity of a typographic layout. Results in [25] demonstrated that visual complexity and perceived order of the layout have an impact on perceived aesthetic impression and concerning preferences for websites. These results are also in line with the well-known fluency effect [26], which describes the observation that objects that are easier to process cognitively are perceived as more aesthetic. A very basic formulation of this idea dates even back to the middle of the last century. Birkhoff's aesthetic measure [27] uses the ratio of order and complexity to measure the aesthetic value of an object.

Thus, if we summarise these arguments, the impression of a clear, clean, structured, organised layout improves the perceived aesthetics. In the following, we call this impression visual clarity.

But items that cover this aspect of product perception can be found in other UX questionnaires as a representation of classical usability dimensions. For example, the UEQ [28], [29], [30] contains an item organised/cluttered, which represents the dimension Efficiency and an item clear/confusing that represents the dimension Perspicuity (how easy is it to understand and learn to use the product). The AttractDiff2 [31] contains an item confusing/clear in the scale Pragmatic Quality (which is merely a representation of classical usability aspects). There are many other examples of this type in other UX questionnaires. For example, the PSSUQ [32] contains an item The organisation of the information on the systems screens was clear as an indicator for the scale information quality. A similar statement The website seems clearly arranged and not cluttered is used in the NRL as part of the scale aesthetics [33].

Intuitively it is quite natural that the visual clarity of a user interface influences also usability judgements. Of course, a clear and structured user interface that contains only a small number of elements is easier to scan than a complex cluttered user interface. Thus, the time to detect the important elements for a task and thus efficiency will be influenced by visual clarity as well [34]. In addition, a high visual clarity will create the impression that the user interface is of low complexity and thus easy to learn.

It is therefore plausible to see here a simple and natural explanation for the connection between perceived usability and aesthetics. If a user interface gives a clear, well-structured impression, this should positively influence the perceived aesthetics as well as the assessment of usability. This would also explain well why there is empirical evidence for both directions (What is beautiful is usable and What is usable is beautiful).

\section{PRE-STUdY}

The goal of this study was to develop items that can be used to measure visual clarity.

\section{A. Participants}

Participants were recruited by sending the link to the online study to a mailing list. 21 persons participated in the study (average age 29.9 years, $67 \%$ females, $33 \%$ males). Participants did not receive any benefits for their participation in the study.

\section{B. Material}

Screenshots (size 1024 x 768 px) of the homepages of four German universities were used as stimuli. We selected pages with varying levels of complexity. Complexity was measured during the selection process by the jpeg-size of the screenshot. This is a common method to get a rough measure of complexity [35], [36], [37]. 


\section{Procedure}

Participants could start the study over a link in the invitation mail. The first screen contained a short introduction to the study. Then the participants could navigate to a screen where they can rate the four screenshots concerning their complexity.

The students provided their subjective rating of visual complexity on a 7-point Likert scale by answering the following question:

\section{The homepage of the university looks simple o o o o o o o complex}

The goal of this rating was to force the participants to think this concept over.

After this rating was submitted a free text question was presented. Participants were asked to list aspects of the four screenshots that are related to visual clarity or visual complexity. Finally, a second free text question about web pages in general was shown. The participants were asked to complete the sentence "A complex web page is for me a page that...”.

\section{Results}

Complexity ratings and jpeg-size showed that the four selected pages indeed varied sufficiently, but the order of the screenshots by perceived visual complexity does not perfectly correspond to the order by jpeg-size:

- Page A: perceived complexity 4.0, size $73 \mathrm{~KB}$

- Page B: perceived complexity 4.3, size $185 \mathrm{~KB}$

- Page C: perceived complexity 4.8, size $191 \mathrm{~KB}$

- Page D: perceived complexity 3.4, size $128 \mathrm{~KB}$

The perceived complexity represents the rating on the 7-point Likert scale described above.

The free text comments were analysed and clustered according to their semantic meaning. Concerning visual clarity two clusters emerged. One cluster contained statements concerning the number of elements on the page. The statements in the second cluster points to the perceived order and alignment of page elements, i.e. the visual organisation of the content.

\section{E. Conclusions}

Thus, the two statements The page has many elements and The information is clearly arranged on the page were selected to represent the concept of visual clarity in the following study.

\section{FIRST STUDY}

The first study tries to investigate if there is a mediator effect of visual clarity on the dependency between perceived aesthetics and perceived usability.

\section{A. Participants}

Participants were recruited over social networks and online forums. 425 persons participated in the study. Average age of the participants was 30.77 years. $43 \%$ of the participants were males, $39 \%$ females and $18 \%$ did not provide gender information.

The dropout rate (percentage of participants that started the onlinestudy but did not submit responses) was $40 \%$.

\section{B. Material}

As stimuli the start pages of 30 public German websites were used. Websites were selected from the three different categories cities, webshops and design agencies to cover a broad spectrum of different cases of use and design styles. For each category a larger sample of pages (around 50) were selected. From this sample 10 pages that varied as to visual complexity (again measured by the size of the saved screen shots in jpeg-format) were selected.

For each of the 30 selected start pages a screen shot with resolution 1024 x 768 was used. Fig. 1 shows two examples of the prepared screenshots for each of the three categories.
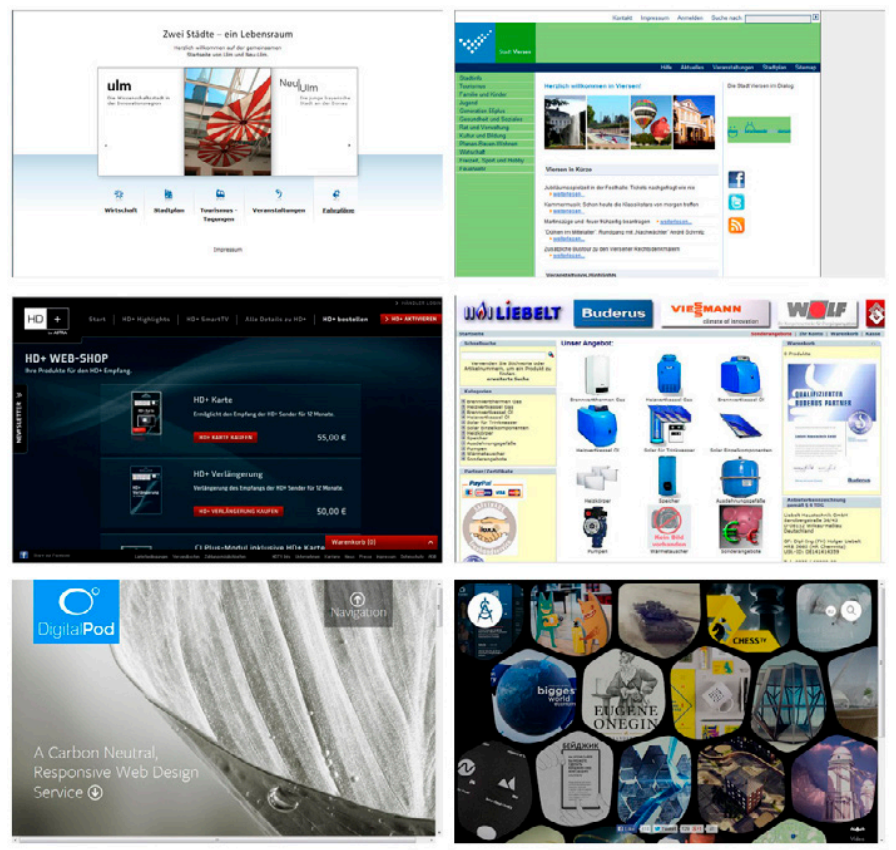

Fig. 1. Six of the used screen shots (on top two homepages of German cities, middle two start pages of web-shops and bottom two homepages of design agencies).

\section{Items}

Four items were used to capture the impression of the shown pages:

\section{- I1: The page has many elements}

- I2: The information is clearly arranged on the page

- I3: I think I would get along well with the web page

- I4: The design of the page is nice

The first and second items represent the concept of visual clarity. As an indicator for visual clarity the mean value of the first two items is used. Here item one is scaled in a reverse order, since agreement to item one means a lower visual clarity. Item three is used as an indicator for the perceived usability of the pages and item four as indicator for visual aesthetics.

All items could be answered on a 7-point Likert scale with the extreme points Do not agree at all and Totally agree.

\section{Procedure}

Each participant was assigned to one of the three website categories. First, a page with general instructions describing the flow of screens in the study and the tasks in each step was presented.

After the participant read this instruction, he or she could start the main part of the study over a link. A randomly selected homepage is shown as a screenshot. Below this screenshot the questions I1 to I4 are presented. After the participant submitted the answers the next randomly selected homepage was presented. This was repeated three times, i.e. each participant evaluated three randomly selected homepages. The restriction to three pages was meant to limit the time required to complete the study and avoid a high dropout rate.

\section{E. Results}

The correlations between the investigated variables were highly 
significant:

- Usability, Aesthetics: $\mathrm{r}=0.44(\mathrm{t}(1072)=16.24, \mathrm{p}<0.001)$

- Clarity, Usability: $\mathrm{r}=0.71(\mathrm{t}(1072)=33.39, \mathrm{p}<0.001)$

- Clarity, Aesthetics: $\mathrm{r}=0.51,(\mathrm{t}(1072)=19.18, \mathrm{p}<0.001)$

The partial correlations between usability and aesthetics if the influence of clarity is controlled is $0.138(\mathrm{t}(1072)=4.57, \mathrm{p}<0.001)$. Thus, if the impact of clarity is considered, then the dependency between the other two variables is much lower. This is a first hint that points in the direction of a mediator effect.

To clarify this in more detail we perform two mediator analyses.

First, we analyse the impact of visual clarity on the influence of aesthetics on usability. The results of the mediator analysis are depicted in Fig. 2. The values without parentheses are the regression coefficients of the simple regressions between variables, i.e. the simple regression of aesthetics on usability, aesthetics on clarity and clarity on usability.

The values in parentheses represent the regression coefficients of the combined regression of aesthetic and clarity on usability. All dependencies are significant with $\mathrm{p}<0.01$ ).

The impact of aesthetics on usability is massively reduced if the mediator variable clarity is considered. The Sobel test [38] shows also a significant mediator effect (Sobel $\mathrm{z}=17.05, \mathrm{p}<0.01$ ).

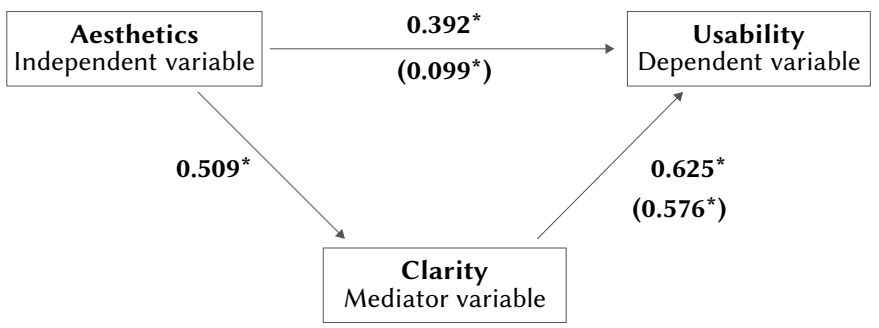

Fig. 2. Dependency between aesthetics and usability considering the impact of visual clarity.

Now we take a look at the opposite direction. The results of the mediator analysis are shown in Fig. 3. Again, there is a significant mediator effect (Sobel $\mathrm{z}=16.78, \mathrm{p}<0.01$ ).

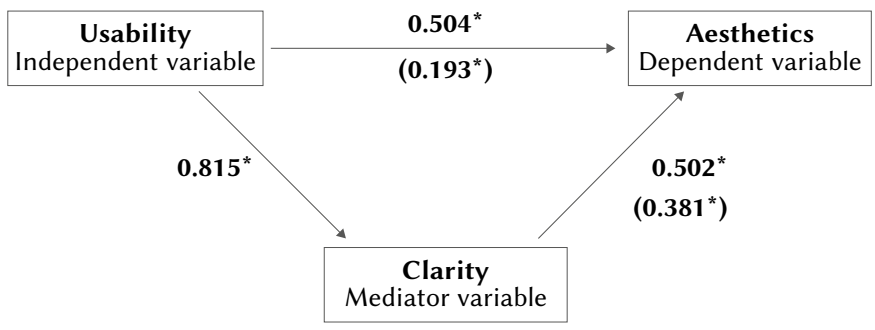

Fig. 3. Dependency between usability and aesthetics considering the impact of visual clarity.

\section{F. Conclusions}

The study found a mediator effect of visual clarity on the dependency between perceived usability and perceived aesthetics in both directions. Thus, the results support the proposed explanation for this dependency.

However, this first study has some methodological limitations worth mentioning. First, the participants rated usability, beauty and visual clarity based on screenshots and did not interact with the pages. This will of course have an impact, especially on the judgements concerning usability.
Second, the ratings concerning usability, aesthetics and clarity were done with simple statements developed in a small pre-study that were expected to cover these concepts.

At least for usability and aesthetics there are established standard questionnaires that allow a more reliable measurement of these concepts. They were not used in this study intentionally to keep the number of items to be answered low and thus to allow the participants to rate more than one screenshot with reasonable effort. But to be able to generalise the results, a replication of the study using standard methods to operationalise these concepts would be helpful.

\section{Construction of a Clarity Scale}

One of the limitations of the first study was that the concepts of usability, aesthetics and visual clarity were not measured with standard questionnaires. For usability and aesthetic impression such questionnaires are available, for the concept of visual clarity this is not the case.

In this study we describe the construction of a scale to measure visual clarity that is embedded in the UEQ+ framework [39]. The UEQ+ is a set of modular UX scales that can be combined to form a UX questionnaire. Thus, the UEQ+ allows researchers to select exactly those UX aspects as scales that are relevant for a concrete product evaluation respectively research question.

The UEQ+ is available free of charge. Scales and required material to set up a questionnaire and analyse the results can be downloaded at ueqplus.ueq-research.org.

\section{A. Selection of an Initial Item Set}

A pool of items meant to represent the concept of visual clarity was constructed by querying several UX experts. After several discussion rounds the constructed item pool was consolidated into a candidate set of 8 items in the UEQ+ format. Thus, each item consists of a pair of terms of opposite meaning that can be rated on a 7-point Likert scale. An example is shown below:

\section{unorganised o o o o o o o organised}

The following candidate items were constructed. The German original version that is used in the study is shown in parentheses:

- difficult to grasp / easy to grasp (schlecht zu erfassen / gut zu erfassen)

- poorly structured / well structured (schlecht gegliedert / gut gegliedert)

- unclear / clear (unklar / klar)

- unstructured / structured (unstrukturiert / strukturiert)

- disordered / ordered (ungeordnet / geordnet)

- unorganised / organised (unorganisiert / organisiert)

- ill-conceived / well-conceived (undurchdacht / durchdacht)

- random / planned (zufällig / geplant)

\section{B. Study for Scale Construction}

An online questionnaire was used to collect some response data concerning the constructed items from a larger sample.

\section{Participants}

69 persons recruited over social media participated in the study. Average age was 29 years, 46 were males and 23 females. Participants did not receive any benefit for their participation.

\section{Procedure}

The online questionnaire consists of four pages. The participants could navigate between these pages by two buttons labelled Next 
and Previous on the bottom of the page. The last page contains just a message that thanks for participation. Data were submitted when the participant clicked on Next on the third page.

The first page gives some general instructions and asks for age and gender of the participant. In addition, participants are instructed only to proceed if they have already used a web shop to purchase goods online.

On page two the participants are asked to name a web shop they have already used for buying goods online. Page three contains the eight items from the set of candidate items.

\section{Results}

Most participants decided to rate Amazon.de (71\%), followed by Zalando.de (14.5\%) and Mediamarkt.de (7.2\%). 5 other shops were just mentioned by one participant.

A factorial analysis (we used the R package psych [40]) showed that a solution with one factor fitted the data quite well (according to the scree plot and the Kaiser-Gutmann criterion). The scree plot of this solution is shown in Fig. 4.

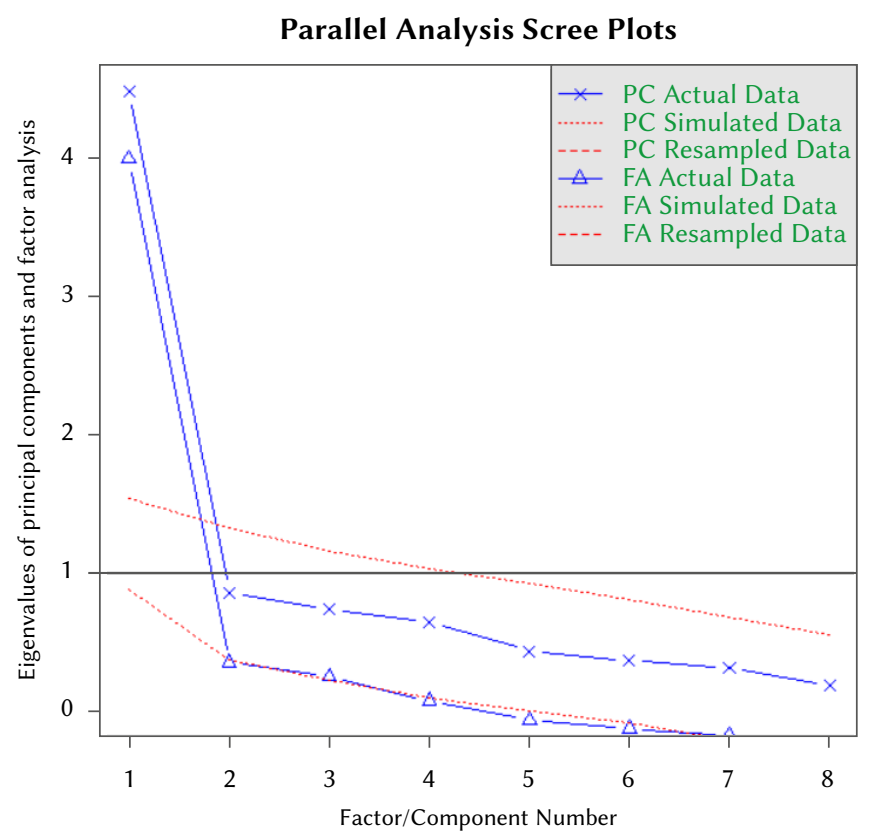

Fig. 4. Screeplot of the factorial analysis.

Thus, the four items that showed the highest loadings on this single factor were chosen to represent the scale for visual clarity (see below).

\section{Constructed UEQ+ Scale}

Using the UEQ+ format the scale to measure visual clarity is:

In my opinion the user interface of the product looks:

$\begin{array}{rll}\text { poorly structured } & \text { о о о о о о о } & \text { well structured } \\ \text { disordered } & \text { о о о о о о о } & \text { ordered } \\ \text { unorganised } & \text { о о о о о о о } & \text { organised } \\ \text { unstructured } & \text { о о о о о о о } & \text { structured }\end{array}$

\section{SECOND Study}

The goal of this study was to replicate Study 1 with a study design that takes the limitations of this previous study into account.

A severe limitation was that the participants of study 1 just rated screenshots of web pages and did not interact with the page. Therefore, we decided to use a running web portal as stimulus and force the participants to use the main functions by giving them a task which must be solved before a rating is possible.

The quality of the rating itself is improved by using common standard questionnaires.

Usability is rated with the System Usability Scale SUS [41].

Aesthetic impression is rated with the short form VISAWI-S [42] of the VISAWI questionnaire and clarity is rated with the new UEQ+ scale that was described in the previous section.

\section{A. Participants}

A link to the online study was sent per mail to 8 classes of a vocational school for technology and design in Lingen (Germany). 168 subjects (135 males, 33 females, average age 22 years) participated in the study. Participation was voluntary and participants received no benefits for taking part in the study.

\section{B. Material}

A fully functional booking portal for holiday trips with real content was used as stimulus.

To create some variety concerning aesthetic impression and clarity four layout variants were created. The CSS of the booking portal was manipulated to create a visually attractive (A), a visually unattractive (B), a version with a high level (C) and low level of clarity (D).

The booking portal was in addition manipulated in a way that the final confirmation step of a holiday booking does not really trigger the booking but navigates to pages that allow to rate the booking experience.

Some examples of pages in the booking portal are shown in Fig. 5 and Fig. 6.

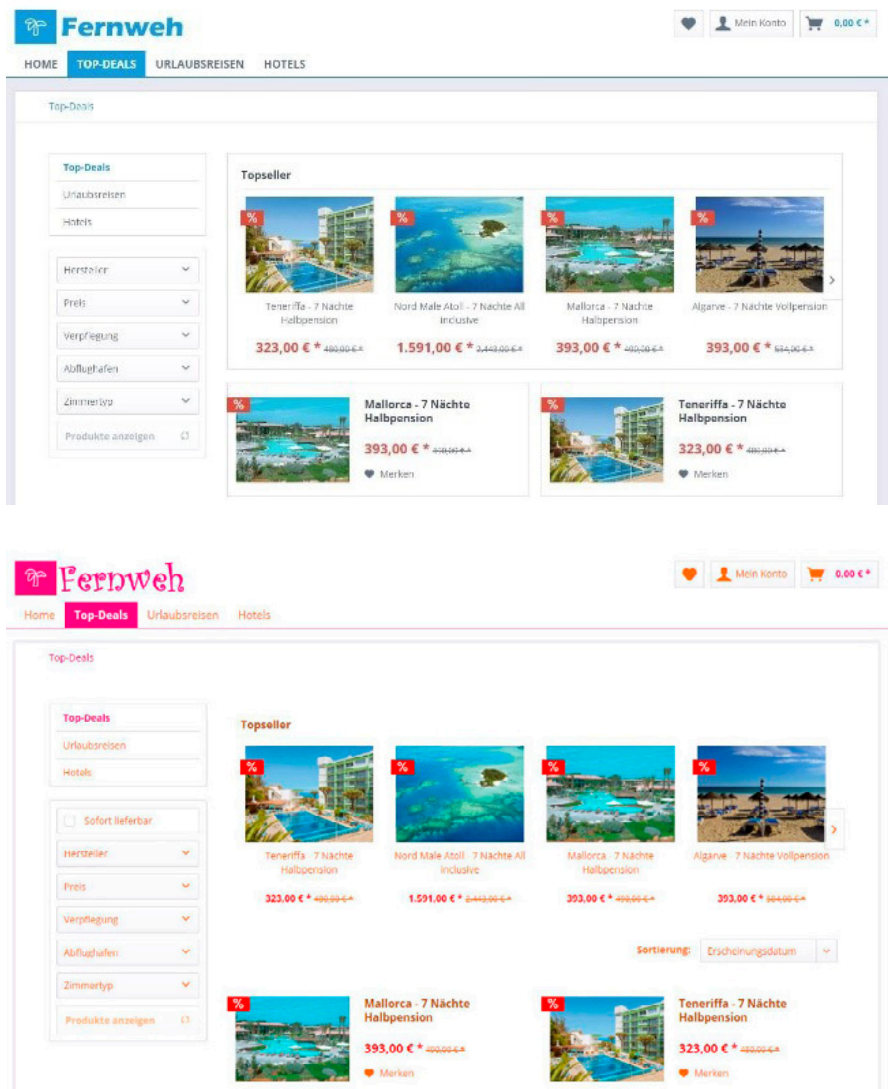

Fig. 5. Search result page for the visually appealing (top) and visually unappealing (bottom) condition. Manipulation of aesthetic appeal was done mainly by changing fonts and font respectively link colours. 


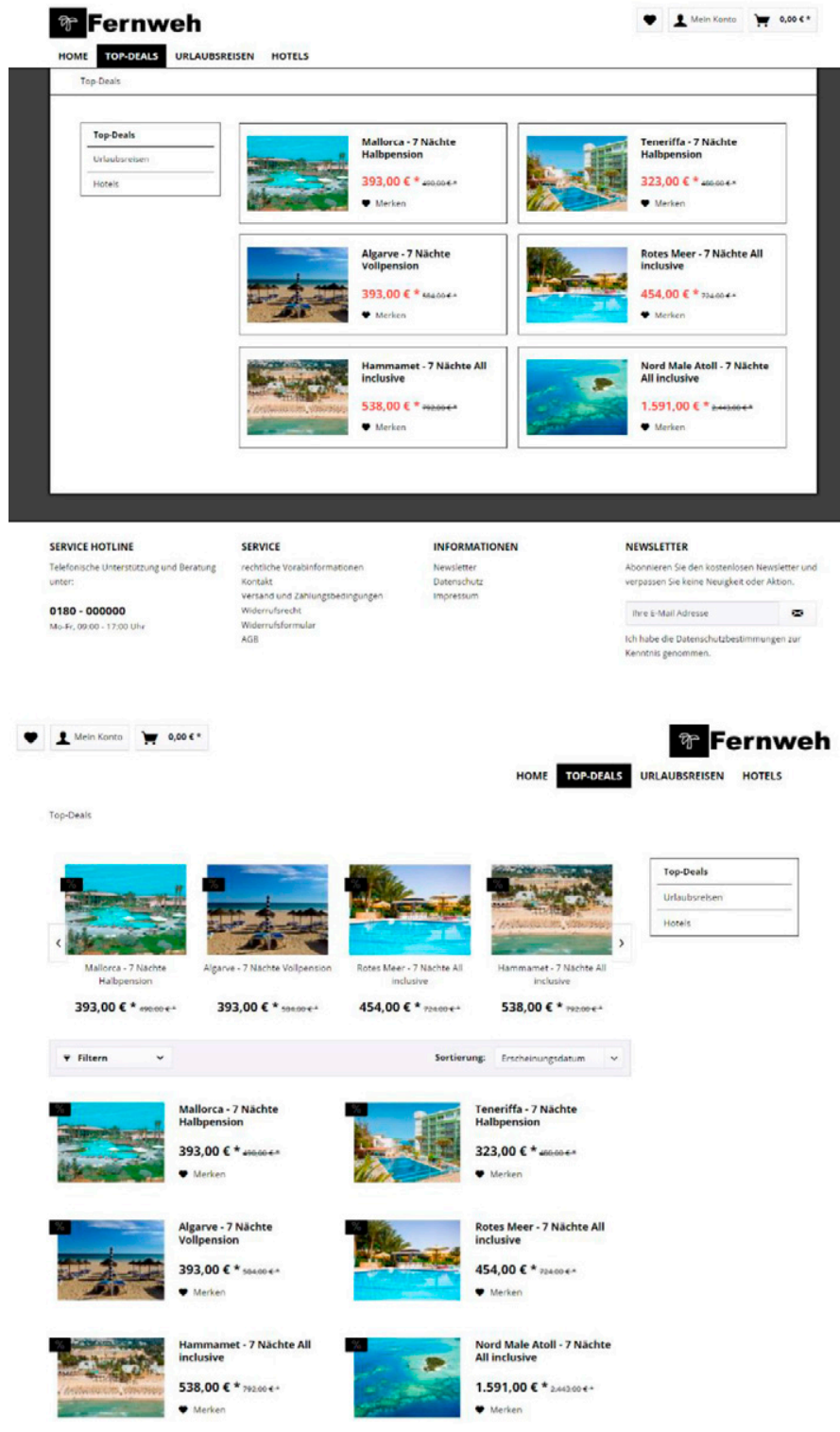

Fig. 6. Search result pages for the versions with high visual clarity (top) and low visual clarity (bottom). Manipulation was done by changing alignment, adding and removing elements and using structuring elements like boxes.

\section{Procedure}

A link to the study was distributed per E-mail. When this link was clicked the participant was randomly assigned to one of the four layout variants. Each participant interacted only with one of these variants during the study.

On the start page of the study participants were instructed to the task. It was explained that they should book a holiday trip according to their personal preferences in a booking portal. They were informed that the confirmation step would not trigger a booking but navigate them to a questionnaire to rate the user experience of the portal.

At the bottom of this start page a link was placed that navigates to a page that asks for age and gender of the participant. From that page the booking portal could be started.

Inside the booking portal the navigation was not restricted. Participants could search for an interesting offer without limitations (all pages were accessible and there was no time limit).
After the participant has decided for a trip and clicked on the final booking step, he or she is redirected to a page that contains the four items of the short form of the VISAWI [42]. Once this has been filled in and the participant has submitted the answer, a page containing the 10 items of the SUS [41] is shown. Submitting the SUS data navigates to a page with the 4 items of the scale to measure clarity.

Once these data have been submitted a final page that allows some optional remarks or free text comments concerning the experiment is shown, and after this final page has been submitted, a page is shown that thanks for the participation.

\section{Results}

Table I shows the mean scale values of the VISAWI-S, SUS and clarity scale for the four layout variants of the booking portal. This data shows that the intended manipulations of the layouts created the intended effect.

TABLE I. Mean Values of the Three Questionnaires Used to Measure Usability (SUS), Aesthetics (VISAWI-S) ANd Visual Clarity (New Scale). The VISAWI-S and Clarity Ratings Range From 1 (Worst) to 7 (Best), While SUS Ratings Range From 0 (Worst) to 100 (Best)

\begin{tabular}{|c|c|c|c|}
\hline Variant & VISAWI-S & SUS & Clarity \\
\hline A (attractive) & $5.57(1.09)$ & $80.51(10.76)$ & $5.82(0.99)$ \\
\hline B (unattractive) & $3.24(1.45)$ & $66.65(15.19)$ & $4.20(1.69)$ \\
\hline C (high clarity) & $4.84(1.17)$ & $82.62(11.15)$ & $6.13(0.79)$ \\
\hline D (low clarity) & $3.85(1.27)$ & $63.10(17.19)$ & $3.67(1.74)$ \\
\hline
\end{tabular}

Now we concentrate on the mediator effect of visual clarity on the dependency of usability and aesthetics, which was the main goal of the replication study.

We first take a look at the correlations between the three variables over all three variants. The following highly significant correlations were observed:

- Aesthetics, Usability: $\mathrm{r}=0.679,(\mathrm{t}(166)=11.91, \mathrm{p}<0.001)$

- Aesthetics, Clarity: $\mathrm{r}=0.715,(\mathrm{t}(166)=13.18, \mathrm{p}<0.001)$

- Usability, Clarity: $\mathrm{r}=0.758,(\mathrm{t}(166)=14.97, \mathrm{p}<0.001)$

The partial correlation between aesthetics and usability, if we control the impact of clarity on both variables, is reduced to 0.299 $(t(168)=4.031, p<0.01)$, which is again a first indicator for the assumed mediator effect.

We now describe the mediator analysis in detail in Fig. 7 and Fig. 8. The values can be interpreted as described above for Fig. 2 .

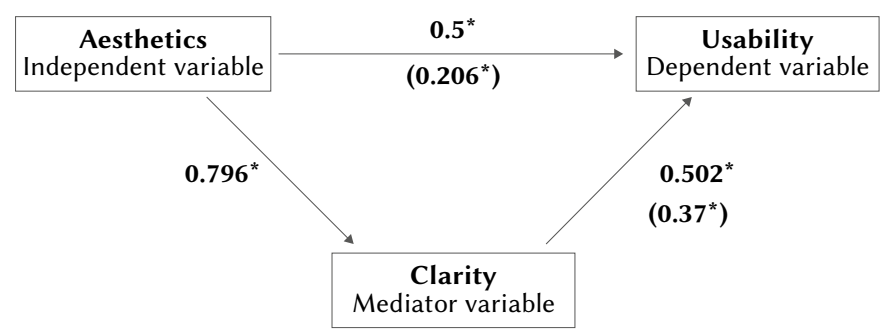

Fig. 7. Dependency between aesthetics and usability considering the impact of visual clarity. Regression coefficients all significantly $>0, p<0.01$ ).

Thus, again the values show that the influence of aesthetics on usability decreases if we consider clarity as a mediator variable. The Sobel test shows a significant mediator effect (Sobel $\mathrm{z}=6.878, \mathrm{p}<0.01$ ).

For the opposite direction of the dependency the Sobel test shows again a significant mediator effect (Sobel $\mathrm{z}=5.465, \mathrm{p}<0.01$ ). 


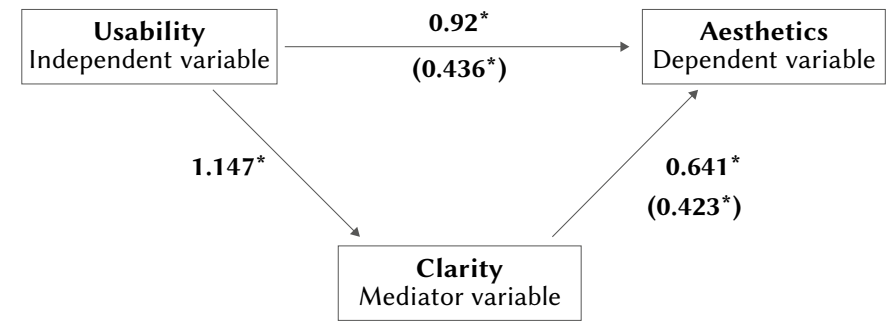

Fig. 8. Dependency between usability and aesthetics considering the impact of visual clarity. Regression coefficients all significantly $>0, p<0.01$ ).

\section{E. Conclusions}

The mediator effect of study 1 could be reproduced. The effect is even a bit stronger (as can be seen by the reduction of the regression coefficients) than in the first study.

Thus, even if participants interact with the pages and if a different way to operationalise the three variables usability, aesthetics and visual clarity is chosen, the expected mediator effect is visible in the data.

\section{SUMMARY}

Several different explanations have been proposed to explain the dependency between perceived usability and perceived aesthetics of a product. We suggest in this paper a new explanation that is based on the observation that items used by some UX questionnaires as an indicator for usability aspects are used in other questionnaires as an indicator for visual aesthetics. What is common to those items is that they describe the impression of clarity or visual simplicity of the layout.

We showed in two different studies that visual clarity acts as a mediator for the dependency between perceived usability and perceived aesthetics. This suggests that the impression of a user interface as clean, aligned, ordered and visually simple acts as a common factor that impacts aesthetics and usability ratings. This explanation allows to explain the dependency of usability and aesthetics in both directions (What is beautiful is usable and What is usable is beautiful) and is conceptually much simpler than other explanations.

Both studies had a quite different setup and the operationalisation of the variable's usability, aesthetics and clarity differed. Thus, the mediator effect could be detected under quite different settings for the study.

A practical advantage of this finding is that it is beneficial to invest a lot of effort in a visually clearly structured user interface during the design of new user interfaces. This will impact usability and aesthetic ratings. The good thing is that this aspect is not so difficult to handle from the point of view of a designer. Well-known design guidelines and heuristics, for example the minimisation of alignment lines in the layout, the number of different visual elements, the variety of elements sizes, etc. can be used to optimise a user interface under this aspect.

\section{REFERENCES}

[1] J.Preece, Y. Rogers, H. Sharp, Interaction Design: Beyond Human-Computer Interaction, Chichester, England: John Wiley and Sons Ltd, 2002.

[2] M. Hassenzahl, "The Effect of Perceived Hedonic Quality on Product Appealingness." International fournal of Human-Computer Interaction 13(4), pp. 481-499, 2001, doi: 10.1207/S15327590IJHC1304_07.

[3] M. Kurosu, K. Kashimura, "Apparent usability vs. inherent usability: experimental analysis of the determinants of the apparent usability", Conference Companion on Human Factors in Computing Systems, Denver, USA, 1995, pp. 292-293, doi: 10.1145/223355.223680.

[4] N. Tractinsky, "Aesthetics and apparent usability: empirically assessing cultural and methodological issues.", Proceedings of the ACM SIGCHI Conference on Human factors in computing systems, New York,
USA: Association for Computing Machinery, pp. 115-122, 1997, doi: 10.1145/258549.258626.

[5] N. Tractinsky, A.S. Katz, D. Ikar, "What is beautiful is usable." Interacting with Computers, vol. 13, pp. 127-145, 2000, doi: 10.1016/S09535438(00)00031-X.

[6] D. Norman, Emotional Design: Why We Love (Or Hate) Everyday Things, Boulder, USA: Basic Books, 2003.

[7] M. Thielsch, R. Haines, L. Flacke, Experimental investigation on the effects of website aesthetics on user performance in different virtual tasks, PeerJ 7:e6516, 2019, doi: 10.7717/peerj.6516.

[8] M. Thielsch, J. Scharfen, E. Masoudi, M. Reuter, "Visual aesthetics and performance: A first meta-analysis.", Mensch und Computer 2019, pp. 199210, doi: $10.1145 / 3340764.3340794$.

[9] W. Ilmberger, M. Schrepp, T. Held, "What kind of cognitive process causes the relationship between aesthetics and usability." in Holzinger, A. (ed.): USAB 2008, LNCS 5298, 2008, pp. 43-54, doi: 10.1007/978-3-54089350-9_4.

[10] A. Tuch, S. Roth, K. Hornbaek, "Is beautiful really usable? Toward understanding the relation between usability, aesthetics, and affect in HCI.", Computers in Human Behavior, vol. 28, no. 5, pp. 1596-1607, 2012, doi: 10.1016/j.chb.2012.03.024.

[11] D. Winter, A. Hinderks, M. Schrepp, J. Thomaschewski, "Welche UX Faktoren sind für mein Produkt wichtig?", Mensch und Computer 2017 - Usability Professionals, Regensburg, Germany, 2017, doi: 10.18420/ muc2017-up-0002.

[12] A. Hinerks, D. Winter, M. Schrepp, J. Thomaschewski, "Applicability of User Experience and Usability Questionnaires.", Journal of Universal Computer Science, vol. 25, no. 13, pp. 1717-1735, 2020, doi: 10.3217/jucs025-13-1717.

[13] A. M. Isen, "Positive affect and decision making", in Lewis, M., Haviland, J.M. (ed.): Handbook of emotions (2nd edition), New York, USA: Guilford Press, pp. 417-435, 2000.

[14] N. Schwarz, "Situated cognition and the wisdom of feelings.", The wisdom of feeling: Psychological processes in emotional intelligence, New York, USA: Guilford Press, pp. 144-166, 2002.

[15] J. Kim, J. K. Moon, "Designing towards emotional usability in customer interfaces - trustworthiness of cyber-banking system interfaces.", in Interacting with Computers, vol. 10, pp. 1-29, 1998, doi: 10.1016/S09535438(97)00037-4.

[16] A. Rafaeli, I. Vilnai-Yavetz, "Instrumentality, aesthetics and symbolism of physical artefacts as triggers of emotion.", in Theoretical Issues in Ergonomics Science, vol. 5, pp. 91-112, 2004, doi: 10.1080/1463922031000086735.

[17] K. K. Dion, E. Berscheid, E. Walster, "What is beautiful is good.", in Journal of Personality and Social Psychology, vol. 24, pp. 285-290, 1972, doi: $10.1037 / \mathrm{h} 0033731$.

[18] A. Dick, C. Dipankar, B. Gabriel, "Memory-Based Inference During Consumer Choice.", in fournal of Consumer Research, vol. 17, pp. 82-93, 1990, doi: 10.1086/208539.

[19] G. T. Ford, R. A. Smith, "Inferential Beliefs in Consumer Evaluations: An Assessment of Alternative Processing Strategies., in fournal of Consumer Research, vol. 14, pp. 363-371, 1987, doi: 10.1086/209119.

[20] C. E. Lance, J. A. LaPointe, A. M. Stewart, "A test of the context dependency of three causal models of halo rater error., in fournal of Applied Psychology, vol. 79, no. 3, pp. 332-340, doi: 10.1037/00219010.79.3.332.

[21] T. Lavie, N. Tractinsky, "Assessing dimensions of perceived visual aesthetics of web sites.", in International fournal of Human-ComputerStudies, vol. 60, pp. 269-298, 2004, doi: 10.1016/j.ijhcs.2003.09.002.

[22] M. Thielsch, M. Mooshagen, "Erfassung visueller Ästhetik mit dem VISAWI., Usability Professionals 2011, Stuttgart, Germany: German UPA e.V., pp.260-265, 2011.

[23] D. C. Ngo, L. S. Teo, J. G. Byrne, "Formalizing guidelines for the design of screen layouts.", in Displays, vol. 21, pp. 3-15, 2000, doi: 10.1016/S01419382(00)00026-3.

[24] G. A. Bonsiepe, "A method for quantifying order in typographic design.", in Journal of Typographic Research, vol. 2, pp. 203-220, 1968.

[25] L. Deng, M. S. Poole, "Aesthetic design of e-commerce web pages Webpage Complexity, Order and preference., in Electronic Commerce Research and Applications, vol 11, no. 4, pp. 420-440, 2012, doi: 10.1016/j. elerap.2012.06.004. 
[26] R. Reber, N. Schwarz, P. Winkielman, "Processing Fluency and Aesthetic Pleasure: Is Beauty in the Perceiver's Processing Experience?", in Personality and Social Psychology Review, vol. 8, no. 4, pp. 364-382, 2004, doi: 10.1207/s15327957pspr0804_3.

[27] G. D. Birkhoff, Aesthetic Measure, Cambridge, USA: Harvard University Press, 1933.

[28] B. Laugwitz, T. Held, M. Schrepp, "Construction and evaluation of a user experience questionnaire., in Symposium of the Austrian HCI and Usability Engineering Group, Herdelberg, Germany: Springer, pp. 63-76, 2008, doi: 10.1007/978-3-540-89350-9_6.

[29] M. Schrepp, A. Hinderks, J. Thomaschewski, "Design and Evaluation of a Short Version of the User Experience Questionnaire (UEQ-S).", in IFIMAI, vol. 4, no. 6, pp.103-108, 2017, doi: 10.9781/ijimai.2017.09.001.

[30] M. Schrepp, A. Hinderks, J. Thomaschewski, "Construction of a benchmark for the User Experience Questionnaire (UEQ).", in International fournal of Interactive Multimedia and Artificial Intelligence, vol. 4, no. 4, pp. 40-44, 2017, doi: 10.9781/ijimai.2017.445.

[31] M. Hassenzahl, M. Burmester, F. Koller, "AttrakDiff: Ein Fragebogen zur Messung wahrgenommener hedonischer und pragmatischer Qualität.", in Mensch \& Computer 2003: Interaktion in Bewegung, Stuttgart, Germany: B. G. Teubner, pp. 187-196, 2003.

[32] J. R. Lewis, "Psychometric evaluation of the post-study system usability questionnaire: The PSSUQ.", in Proceedings of the Human Factors and Ergonomics Society Annual Meeting, vol. 36, no. 16, pp. 1259-1260, 1992, doi: $10.1177 / 154193129203601617$.

[33] M. Thielsch, I. Blotenberg, R. Jaron, "User Evaluation of Websites: From First Impression to Recommendation", in Interaction with Computers, vol. 26, pp. 89-102, 2014, doi: 10.1093/iwc/iwt033.

[34] R. Rosenholtz, Y. Li, L. Nakano, "Measuring visual clutter.", in fournal of Vision, vol. 7, no. 2, pp.1-22, 2007, doi: 10.1167/7.2.17.

[35] K. Müller, M. Schrepp, "Visuelle Komplexität, Ästhetik und Usability von Benutzerschnittstellen.", Mensch \& Computer 2013 - Interaktive Vielfalt, München, Germany: Oldenbourg Verlag, pp. 211-220, 2013, doi: 10.1524/9783486781229.211.

[36] T. K. Comber, J. R. Maktby, "Screen complexity and user design preferences in windows applications.", in Harmony through working together: proceedings of OZCHI 94, pp.133-137, 1994.

[37] D. C. Donderi, "Visual Complexity: A Review.", in Psychological Bulletin 2006, vol. 132, pp. 73-79, 2006, doi: 10.1037/0033-2909.132.1.73.

[38] M. Sobel, "Asymptotic confidence intervals for indirect effects in structural equation modelling.", in Sociological Methodology, vol. 13, pp. 290-312, 1982, doi: 10.2307/270723.

[39] M. Schrepp, J. Thomaschewski, "Design and Validation of a Framework for the Creation of User Experience Questionnaires.", in International fournal of Interactive Multimedia and Artificial Intelligence, vol. 5, no. 7, pp. 88-95, 2019, doi: 10.9781/ijimai.2019.06.006.

[40] W. Revelle, psych: Procedures for Psychological, Psychometric, and Personality Researchm, Illionis, USA: Northwestern University, 2018, https://CRAN.R-project.org/package=psych Version $=1.8 .12$.

[41] J. Brooke, "SUS-A quick and dirty usability scale., in Usability evaluation in industry, vol. 189 , no. 194, pp. 4-7, 1996, doi: 10.1201/978149871041135 .

[42] M. Moshagen, M. Thielsch, "A short version of the visual aesthetics of websites inventory", in Behaviour \& Information Technology, vol. 32, no. 12, pp. 1305-1311, 2013, doi: 10.1080/0144929X.2012.694910.

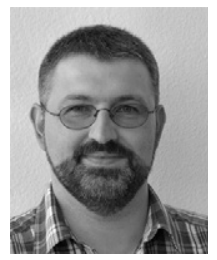

Martin Schrepp

Martin Schrepp has been working as a user interface designer for SAP SE since 1994. He finished his diploma in mathematics in 1990 at the University of Heidelberg (Germany). In 1993 he received a PhD in Psychology (also from the University of Heidelberg). His research interests are the application of psychological theories to improve the design of software interfaces, the application of Design for All principles to increase accessibility of business software, measurement of usability and user experience, and the development of general data analysis methods. He has published several papers concerning these research fields.

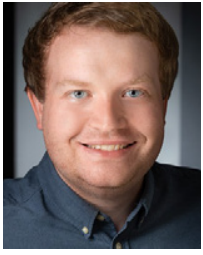

\section{Raphael Otten}

Raphael Otten was born on Februar 19, 1990 in Lingen, Germany. He studied business informatics in the year 20112014 at the University of Applied Sciences Osnabrück, Germany. He graduated with a Bachelor of Science in the year 2014. After that, he studied media informatics in the years 2014-2019 at the University of Applied Sciences Emden/Leer. He graduated with a Master of Science in the year 2019. Since 2008, Raphael Otten is working as a Backend Developer at connectiv! eSolutions GmbH.

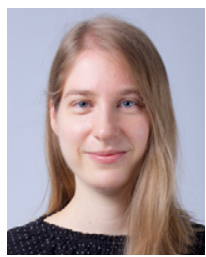

Kerstin Blum

Kerstin Eva Blum (formerly Mueller) was born on June 23rd, 1986 in Nürtingen, Germany. She studied psychology in the years 2007-2010 at the University of Konstanz, Germany. She graduated with a Bachelor of Science in the year 2010. After that, she studied psychology in the years 2010-2013 at the Ruprecht-Karls University of Heidelberg with a focus on "organizational behavior and adaptive cognition". She graduated with a Master of Science in the year 2013. Since 2013, Kerstin Blum is working as a User Experience Designer in various application areas at SAP SE.

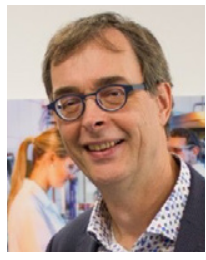

Jörg Thomaschewski

Jörg Thomaschewski received a $\mathrm{PhD}$ in physics from the University of Bremen (Germany) in 1996. He became Full Professor at the University of Applied Sciences Emden/ Leer (Germany) in September 2000. His research interests are human-computer interaction, e-learning, and software engineering. Dr. Thomaschewski is the head of the research group “Agile Software Development and User

Experience”. 